\title{
Chapter 16 \\ Professional Development of Mathematics Teachers: Through the Lens of the Camera
}

\author{
Ronnie Karsenty
}

\begin{abstract}
The VIDEO-LM project (Viewing, Investigating and Discussing Environments of Learning Mathematics), developed at the Weizmann Institute of Science in Israel, is aimed at enhancing secondary mathematics teachers' reflection and mathematical knowledge for teaching. In the project, videotaped lessons serve as learning objects and sources for discussions with teachers. These discussions are guided by an analytic framework, comprised of six viewing lenses: mathematical and meta-mathematical ideas; goals; tasks; dilemmas and decision making; interactions; and beliefs. To assess and characterize the impact of the project, data was collected from 17 different implementations of in-service VIDEO-LM courses around the country conducted by facilitators specifically qualified for this pursuit. This paper reports on some of the findings, with particular reference to possible mechanisms that can explain the processes of change that teachers undergo.
\end{abstract}

Keywords Video-based professional development • Secondary mathematics teachers - Reflection - Mathematical knowledge for teaching

\subsection{Introduction}

Video has been used as a tool for teacher education and professional development (PD) for the past 50 years, however the focus and methods of its uses has changed considerably over time (Sherin 2004; see Fig. 16.1). Presently, the low cost of portable easy-to-use digitized video recording devices, combined with accessible means of editing and exchanging clips, has increased the dissemination of this technology within PD programs for mathematics teachers around the world [e.g., Mathe sicher können in Germany; the Problem-Solving Cycle and the Learning and Teaching Geometry programs in the USA (Borko et al. 2011); MILE in the Netherlands (Goffree and Oonk 2001); and Effective Mathematics Teaching and

\footnotetext{
R. Karsenty $(\bowtie)$

Weizmann Institute of Science, Rehovot, Israel

e-mail: ronnie.karsenty@weizmann.ac.il

(C) The Author(s) 2018

G. Kaiser et al. (eds.), Invited Lectures from the 13th International Congress

on Mathematical Education, ICME-13 Monographs,

https://doi.org/10.1007/978-3-319-72170-5_16
} 
CBL in Australia (Clarke et al. 2013)]. Online video resources are now largely available to educators (MET in the USA and Teachers Media in UK are prominent examples) and international symposia are dedicated to the use of video in professional development for mathematics teachers (e.g., http://www.weizmann.ac.il/ conferences/video-lm2014).

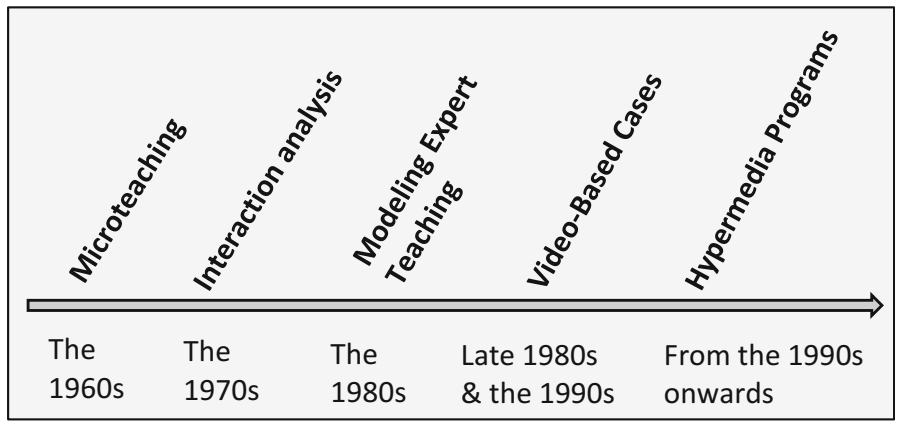

Fig. 16.1 Changes in video uses in teacher education (based on Sherin 2004)

The affordances of videotaped episodes as a source for teacher learning have been investigated in a growing number of studies (e.g., Brophy 2004; Borko et al. 2011; Coles 2014; Gaudin and Chaliès 2015; Nemirovsky and Galvis 2004; Santagata and Yeh 2013; Sherin and van Es 2009). Sherin and van Es (2009) claim that "teachers benefit from opportunities to reflect on teaching with authentic representations of practice" (p. 21); Brophy (2004) argues that video can introduce "the complexity and subtlety of classroom teaching as it occurs in real time" (p. 287); and Nemirovsky and Galvis (2004) suggest that "because of the unique power of video to convey the complexity and atmosphere of human interactions, video case studies provide powerful opportunities for deep reflection" (p. 68). All of these scholars emphasize the role of video as a window to the authentic practice of teaching, which allows teachers to focus on complex issues that may be unpacked through observing, re-observing, and reflecting on specific occurrences.

Three main directions can be identified within programs that use videotaped episodes from mathematics lessons as resources for teacher development. First, video is utilized for introducing new curricula, activities, pedagogical strategies, etc. This target is mainly implemented through supplying teachers with video cases that model and demonstrate how teaching the new curricula or using the pedagogical strategies may be enacted (e.g., Seago et al. 2010). A second direction is using videotaped lessons as a source for feedback and evaluation. Teachers watch videotapes from their own classrooms and discuss them with colleagues or instructors, often with the use of pre-constructed standard-based rubrics such as those developed by Danielson (2013) or Hill et al. (2008). The third direction is using videotaped episodes to enhance teachers' proficiency to notice, understand 
and discuss students' mathematical thinking (Sherin et al. 2011), usually in the form of "video clubs" (van Es and Sherin 2008).

The VIDEO-LM Project (Viewing, Investigating and Discussing Environments of Learning Mathematics) is aimed at a fourth direction: the elaboration and use of tools for reflection on the mathematics teaching practice through the development of a productive language that supports deep peer conversations. The project also aims at promoting the development and enrichment of mathematics knowledge for teaching, in the sense defined by Ball et al. (2008).

In this paper, I describe the project and its theoretical roots. I then introduce the framework of analysis, called the six-lens framework, developed to achieve the project's aims. I present findings from an evaluative study conducted to assess the impact of the project. Finally, I suggest possible mechanisms that can explain the processes of change that teachers undergo.

\subsection{The VIDEO-LM Project: Rationale, Theoretical Roots, and Framework}

Teaching is known to be a rather lonely profession. Despite participation in professional communities, online forums, and other forms of communication and collaboration with other teachers, the reality is that the vast majority of teachers are the "solo adult actors" in their classrooms, where they spend the lion's share of their professional life. In many countries teachers seldom get the chance to watch their peers in action once the pre-service period is over. This is not merely a social deficit but also a barrier to certain processes of professional evolution embedded in peer learning in situ. The VIDEO-LM project, developed at the Weizmann Institute of Science in Israel, is a research-based PD program for secondary mathematics teachers that creates opportunities for teachers to watch whole lessons given by other teachers. The project uses a collection of videotaped lessons, which serve as learning objects and sources for discussions with teachers. Since teachers do not watch themselves, as is frequently done in video clubs, but rather observe videotaped lessons of unknown teachers, the videos are taken, in a sense, as "vicarious experiences" that allow for indirect exploration of one's own perceptions on the practice of mathematics teaching through the observation of "remote" teaching events. This is done in a supportive atmosphere that does not focus on evaluative feedback.

The project is rooted in two theories: Schoenfeld's $(1998,2010)$ Teaching in Context theory and the theoretical framework of Mathematical Knowledge for Teaching (MKT; Ball et al. 2008). According to the Teaching in Context framework (Schoenfeld 1998, 2010), teaching is goal-oriented; teachers strive to achieve various types of goals and are constantly modifying and changing their goals in correspondence with classroom realities. The theory asserts that teachers have a body of knowledge resources they can call upon for both expected and unexpected situations and that teachers, like everyone else, have a set of orientations, i.e., predispositions and beliefs about mathematics, about students, and about teaching. 
This triad of goals, resources, and orientations monitors teachers' decision-making processes and shapes their choice of actions.

The MKT framework, proposed by Ball et al. (2008) and refined by Hill et al. (2008), is comprised of two categories, Subject Matter Knowledge and Pedagogical Content Knowledge, further divided into six sub-categories. This framework is valuable both as a conceptualization tool of the kind of knowledge we wish to enhance within a PD setting and as an analysis tool that allows a scrutinized look at what teachers are focusing on during PD sessions, as I shall demonstrate in Sect. 16.4.

\subsubsection{The Six-Lens Framework}

In light of these theoretical frameworks, we suggest that teachers can and should be actively involved in a deep reflection and analysis of their own (and others') goals, resources, and orientations and of their mathematical knowledge for teaching. Following previous initial experimentation with video-based discussions that centralize these ideas (Arcavi and Schoenfeld 2008), we designed a framework consisting of six analytical tools with which mathematics teachers can reflect on a videotaped lesson. We call these tools lenses, to emphasize their use as means of observation, in the dual sense of watching an occurrence but also commenting on it. Viewing a lesson through a certain lens implies shedding light on a specific feature of the mathematics teaching practice. Table 16.1 presents this six-lens framework (henceforth: SLF), consisting of the following components: mathematical and meta-mathematical ideas; goals; tasks and activities; interactions; dilemmas and decision-making; and beliefs about mathematics teaching. Table 16.1 outlines the focus of observation activities around each of these lenses, and exemplifies the sort of questions that direct discussions with teachers.

\subsubsection{Features of Using SLF in Video-Based PD Sessions}

The SLF framework was designed with a particular desired learning environment in mind. We envisioned a supportive and nonthreatening setting in which a group of teachers feels comfortable enough to elicit ideas and thoughts, while opportunities are created for deep reflection on practice. Our aim was that the activities of watching and analyzing videotaped lessons will lead to forming peer groups that are highly engaged in core issues of the mathematics teaching profession. Therefore, we explicitly defined the use of SLF in PD sessions around the following features and norms:

- SLF is not evaluative in nature and is not used for the purpose of providing feedback. In line with the works of Jaworski (1990) and Coles (2013), the use of SLF attempts to establish nonjudgmental norms of discussion through the redirection of highly evaluative comments into "issues to think about". This is closely connected to the next feature. 
Table 16.1 The Six-Lens Framework (SLF)

\begin{tabular}{|c|c|c|}
\hline $\begin{array}{l}\text { Lenses for observing } \\
\text { a videotaped } \\
\text { mathematics lesson }\end{array}$ & $\begin{array}{l}\text { The focus of activities around each } \\
\text { lens }\end{array}$ & $\begin{array}{l}\text { Examples of questions that direct } \\
\text { teachers' discussions }\end{array}$ \\
\hline $\begin{array}{l}\text { Mathematical and } \\
\text { meta-mathematical } \\
\text { ideas }\end{array}$ & $\begin{array}{l}\text { Scanning the space of relevant ideas, } \\
\text { concepts, and procedures, as well as } \\
\text { meta-mathematical ideas (e.g., one } \\
\text { counter example is sufficient to } \\
\text { refute a conjecture) that may be } \\
\text { associated with the lesson's topic }\end{array}$ & $\begin{array}{l}\text { - Which ideas did the filmed teacher } \\
\text { bring forward in the lesson? Which } \\
\text { ideas were left out? How can this } \\
\text { decision be explained? } \\
\text { - Which meta-mathematical notions } \\
\text { were evident in the lesson? }\end{array}$ \\
\hline $\begin{array}{l}\text { Explicit and implicit } \\
\text { goals }\end{array}$ & $\begin{array}{l}\text { Attributing goals that may underlie } \\
\text { the teacher's actions or decisions, on } \\
\text { the basis of what was observed in } \\
\text { the video. Rather than "scientifically } \\
\text { verifying true goals", the aim is to } \\
\text { sharpen awareness of different } \\
\text { possible goals and negotiate the pros } \\
\text { and cons of preferring certain goals } \\
\text { over others. }\end{array}$ & $\begin{array}{l}\text { - Try to identify the goals that you } \\
\text { think the filmed teacher was } \\
\text { attempting to achieve. Show } \\
\text { evidence from the video to support } \\
\text { your assertion. } \\
\text { - Did you notice a moment when the } \\
\text { teacher's goals have changed or a } \\
\text { new goal was added? Why do you } \\
\text { think this happened? }\end{array}$ \\
\hline Tasks and activities & $\begin{array}{l}\text { Conducting an "a posteriori task } \\
\text { analysis": discussing features of the } \\
\text { task and how it was enacted by the } \\
\text { filmed teacher and students. } \\
\text { Noticing if and when it develops } \\
\text { differently than expected. }\end{array}$ & $\begin{array}{l}\text { - Observe and document how the } \\
\text { task is introduced and carried out } \\
\text { and how the teacher addresses } \\
\text { students' reactions. } \\
\text { - What may be the benefits and } \\
\text { pitfalls in bringing this task to class? }\end{array}$ \\
\hline $\begin{array}{l}\text { Interactions with } \\
\text { students }\end{array}$ & $\begin{array}{l}\text { Observing and analyzing if and how } \\
\text { the filmed teacher poses further } \\
\text { questions to those of the task; } \\
\text { listens to (or ignores) comments or } \\
\text { difficulties raised by students; } \\
\text { manages discussions; delegates } \\
\text { responsibilities in the process of } \\
\text { knowledge generation. }\end{array}$ & $\begin{array}{l}\text { - How does the filmed teacher } \\
\text { navigate students' responses during } \\
\text { the mathematical activity? What } \\
\text { kind of questions does the teacher } \\
\text { ask? Who gets permission to speak? } \\
\text { - Characterize the teacher's feedback } \\
\text { to students. }\end{array}$ \\
\hline $\begin{array}{l}\text { Dilemmas and } \\
\text { decision-making }\end{array}$ & $\begin{array}{l}\text { Uncovering situations of dilemma } \\
\text { (i.e., when there is no evident } \\
\text { optimal course of action) that the } \\
\text { filmed teacher seemed to have faced } \\
\text { during the lesson. Discussing the } \\
\text { decisions taken in order to resolve } \\
\text { these dilemmas, and their } \\
\text { consequent tradeoffs. }\end{array}$ & $\begin{array}{l}\text { - Did you notice a dilemma during the } \\
\text { lesson? What did the teacher decide } \\
\text { to do? Are there alternatives you } \\
\text { can think of for this decision? } \\
\text { - What may be the constraints and } \\
\text { affordances of the teacher's choice } \\
\text { and of the suggested alternative } \\
\text { paths? }\end{array}$ \\
\hline $\begin{array}{l}\text { Beliefs about } \\
\text { mathematics } \\
\text { teaching }\end{array}$ & $\begin{array}{l}\text { Eliciting orientations, beliefs and } \\
\text { values that may be attributed to the } \\
\text { filmed teacher on the basis of the } \\
\text { video. Unpacking implicit messages } \\
\text { that may be conveyed to students } \\
\text { through the teacher's } \\
\text { communications and actions. }\end{array}$ & $\begin{array}{l}\text { - What may be the filmed teacher's } \\
\text { views about the nature of } \\
\text { mathematics as a discipline? } \\
\text { - How does the teacher perceive his } \\
\text { or her role? What may be the } \\
\text { teacher's ideas about what "good } \\
\text { mathematics teaching" is? What } \\
\text { does the teacher think about the } \\
\text { students' role as learners? }\end{array}$ \\
\hline
\end{tabular}


- An SLF-based discussion pre-accepts a basic working assumption that the filmed teacher is acting in the best interest of his/her students. Thus, observers are required to "step into the shoes" of the filmed teacher in an attempt to understand his/her goals, decisions, and beliefs, maintaining a respectful conversation. This viewpoint allows for deeper layers of reflection than those entailed in comments such as "she's doing it all wrong".

- SLF does not pursue the demonstration of "best practice". This is intentional; we believe that for different teachers there may be different best practices and that these differences may be linked to personal, contextual, and cultural settings. Our aim is to choose lessons that can serve as springboards for meaningful discussions on different aspects of practice, rather than on alignment with criteria of what teaching should look like. In this sense, we adopted the term "better than best practice" coined by Lefstein and Snell (2014).

- SLF is deeply rooted in the subject matter of mathematics and shuns generic discussions on teaching. Issues of classroom management, the teachers' body language and other generic aspects are marginal, if not completely absent, during discussions around the screened lessons. Instead, SLF refers to what lies at the heart of mathematics teaching, such as mathematical concepts and ideas, meta-mathematical concerns, possible targets of mathematics lessons, and beliefs about mathematics teaching.

In addition, the following two choices regarding the use of SLF are important to mention:

- SLF is a teacher-centered framework, i.e., the focus is on the filmed teacher's actions and choices. Students' voices and actions are taken into account within the interaction lens; however, the lion's share of an SLF-based discussion is dedicated to what the teacher is doing. In this regard, SLF is significantly different from the noticing framework (Sherin et al. 2011) mentioned earlier.

- SLF does not refer to clips or short episodes edited from a lesson; rather, the units of analysis for teachers' discussions are whole lessons, in which a more comprehensive "story" can unfold, with a beginning, a development of a process, and a closure. This characteristic marks SLF as unique amongst other frameworks used in most PD programs.

\subsection{Exploring Possible Gains of Video-Based Discussions Directed by the SLF Framework}

\subsubsection{VIDEO-LM Courses for Secondary Mathematics Teachers}

During the 2012-13 academic year, we conducted two pilot courses for mathematics teachers. Based on this pilot, we refined the design of the course to obtain a model which has since then been implemented in 29 new PD courses (7, 8, and 14 
in the academic years of 2013-14, 2014-15, and 2015-16, respectively). The course consists of 30 academic hours, usually configured as 7-8 monthly sessions of 4-4.5 h each, and is led by a VIDEO-LM facilitator who has been specifically qualified for this pursuit, in consultation with the development team. In each session, the teachers watch a videotaped mathematics lesson. Several modes of "watching and discussing" may apply, according to a predesigned session plan (e.g., watching together or in small groups, focusing on different lenses, watching the whole lesson uninterruptedly vs. breaking it to sequenced episodes). The collection of videotaped lessons (mostly filmed by the VIDEO-LM team in Israel and a few videos from Japan and USA with Hebrew subtitles) as well as supplementary materials such as the tasks used in the lesson and lesson graphs describing the flow of the lesson are available on the VIDEO-LM website. ${ }^{1}$

\subsubsection{Research Aim and Questions}

Following the growing demand for VIDEO-LM courses, we designed several studies aiming to explore possible impacts of these courses on the participating teachers. Two of the research questions (RQ) investigated were the following:

$R Q I$. What may be the gains of video-based teacher discussions around the SLF framework, in terms of the teachers' MKT?

$R Q$ II. To what degree do VIDEO-LM sessions stimulate reflections and deep conversations about the teaching practice?

\subsubsection{Data Collection and Analysis}

Data was collected from the 17 VIDEO-LM professional development courses that were conducted during 2012-2015 at nine different sites in Israel. The analyses of data are still ongoing, and in this paper I report on selected findings from five courses. Details on these courses and the data collection means used appear in Table 16.2.

All participants were secondary school mathematics teachers with different levels of experience-from new teachers to experienced teachers. Participation was recognized by the Ministry of Education for accruing credential points for promotion. Although courses were somewhat different from one another, according to each facilitator's approach and the local dynamics of the group, all were aligned with the course model described above, and in all of them SLF was used as a base for peer discussions.

\footnotetext{
${ }^{1}$ http://adasha.weizmann.ac.il.
} 
Table 16.2 Courses details and data collection means

\begin{tabular}{l|l|l|l|l|l}
\hline Site & Year & Location & $\begin{array}{l}\text { No. of } \\
\text { participants }\end{array}$ & $\begin{array}{l}\text { Written data } \\
\text { (reflections or } \\
\text { feedback } \\
\text { questionnaires })\end{array}$ & $\begin{array}{l}\text { Documentation } \\
\text { of sessions }\end{array}$ \\
\hline (a) & $2012-13$ & WIS & 10 & $\checkmark$ & $\begin{array}{l}\text { Video of all } \\
\text { sessions }\end{array}$ \\
\hline (b) & $2013-14$ & WIS & 12 & $\checkmark$ & $\begin{array}{l}\text { Video of all } \\
\text { sessions }\end{array}$ \\
\hline (c) & $2014-15$ & $\begin{array}{l}\text { RTC, large city } \\
\text { in the center of } \\
\text { Israel }\end{array}$ & 17 & $\checkmark$ & $\begin{array}{l}\text { Video or audio } \\
\text { of several } \\
\text { sessions }\end{array}$ \\
\hline (d) & $2014-15$ & $\begin{array}{l}\text { RTC, town in } \\
\text { the center of } \\
\text { Israel }\end{array}$ & 11 & $\checkmark$ & $\begin{array}{l}\text { Video or audio } \\
\text { of several } \\
\text { sessions }\end{array}$ \\
\hline (e) & $2014-15$ & $\begin{array}{l}\text { RTC, town in } \\
\text { the north of } \\
\text { Israel }\end{array}$ & 11 & - & $\begin{array}{l}\text { Video or audio } \\
\text { of several } \\
\text { sessions }\end{array}$ \\
\hline
\end{tabular}

WIS Weizmann Institute of Science; RTC Regional Teacher Centre

As shown in Table 16.2, the data collected included video and audio documentation of PD sessions and written reflections or feedback questionnaires submitted by teachers at the end of the course (these submissions were part of the course assignments; the decision whether to include written reflections or feedback questionnaires in the final assignments was left to the facilitator in each site). The analysis of the data was carried out using various qualitative content analysis methods. Each method was applied to selected parts of the data, according to both availability of data at the time of analysis and the target of the analysis. Two analysis methods that are relevant to findings reported in this paper are described below.

(1) In order to answer RQ I, we performed a sequence of steps as follows (Karsenty et al. 2015; Nurick 2015): Transcribing video or audio records of PD sessions; tracing all utterances of participants' associated with MKT (i.e., unpacking mathematical concepts or relating to teaching these concepts); grouping utterances into units of analysis that share similar ideas; using the units to form "discussion maps" that convey the evolution of knowledge throughout different parts of sessions (examples follow in the Findings section); and comparing utterances in the discussions before and after watching the video using the six MKT categories. This type of analysis was performed on data from Sites (a) and (b).

(2) In order to answer RQ II, we performed a sequence of steps based on grounded theory methods (Glaser and Strauss 1967) as follows (Karsenty and Schwarts 2016; Schwarts 2016): Reading all the documented material-both spoken and written-relating to a the same lesson watched in various sites and identifying common themes; categorizing participants' utterances by the themes identified; 
defining major themes according to considerations of prevalence and interest, merging categories where necessary; building "theme narratives" in order to characterize teachers' reactions in each category; and reexamining the narratives in search for different types of reflections that may be identified. This type of analysis was performed on data from Sites (a), (c), (d) and (e).

\subsection{Selected Findings}

\subsubsection{Growth of Mathematical Knowledge for Teaching}

In the third session conducted at Site (a), teachers watched an episode from a lesson on the commutative and associative laws given in a seventh grade heterogeneous class. Prior to watching the video, teachers were asked to elicit any mathematical ideas that may be associated with the topic of the commutative and associative laws. They suggested a fairly wide range of ideas, from the simple fact that addition and multiplication satisfy both laws, while subtraction and division do not, through various models that demonstrate the laws, to efficient solutions of multi-term exercises using the laws. It appeared that most teachers perceived the topic as natural and intuitive for students, at least at the numerical level. The discussion was coded in terms of the MKT categories (Ball et al. 2008): Each unit of analysis was coded as reflecting Common Content Knowledge (CCK), Specialized Content Knowledge (SCK), Knowledge of Content and Teaching (KCT), etc. The following excerpt demonstrates a unit of analysis coded as KCS (Knowledge of Content and Students):

64 T1: In seventh grade it's difficult to construct a serious generalization, so you smooth it over to things that work or don't work. As ideas, the associative and commutative laws are too early for seventh grade and it's difficult to create learning

65 T2: There is use in it, applications. For example $99+3232+1$. A student that looks at it intuitively will do it

66 T3: They will do it without us calling it the commutative law and generalizing it

The part of the discussion before the video was screened was formed into two "discussion maps", one of which is presented in Fig. 16.3. Each unit was colored according to its MKT categorization using the color key introduced in Fig. 16.2. The discussion map clearly shows that prior to watching the video, teachers mainly demonstrated pedagogical content knowledge. The other discussion map, not appearing herein due to space limitations, conveys the same conclusion.

In the videotaped episode, the teacher asked the class whether operations that satisfy the commutative law necessarily satisfy the associative law as well and vice 
versa. The students' spontaneous collective answer was "yes". The teacher then introduced operation tables that were shown to be counterexamples to this conjecture (see Fig. 16.4) and led a discussion resulting in the conclusion that the laws are not interdependent.

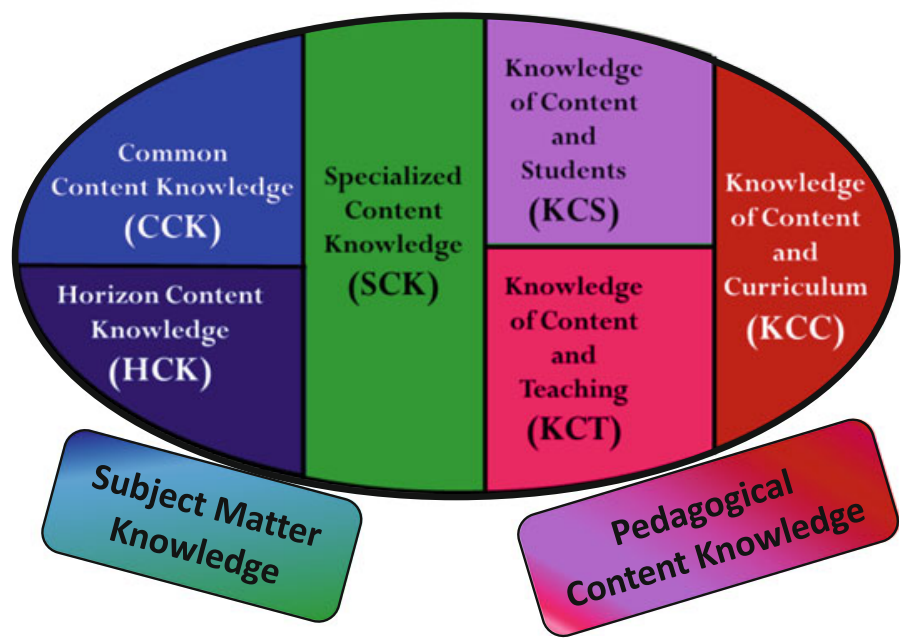

Fig. 16.2 Components of MKT (adapted from Ball et al. 2008, p. 403; For interpretation of the references to color in this figure, the reader is referred to the web version of this article)

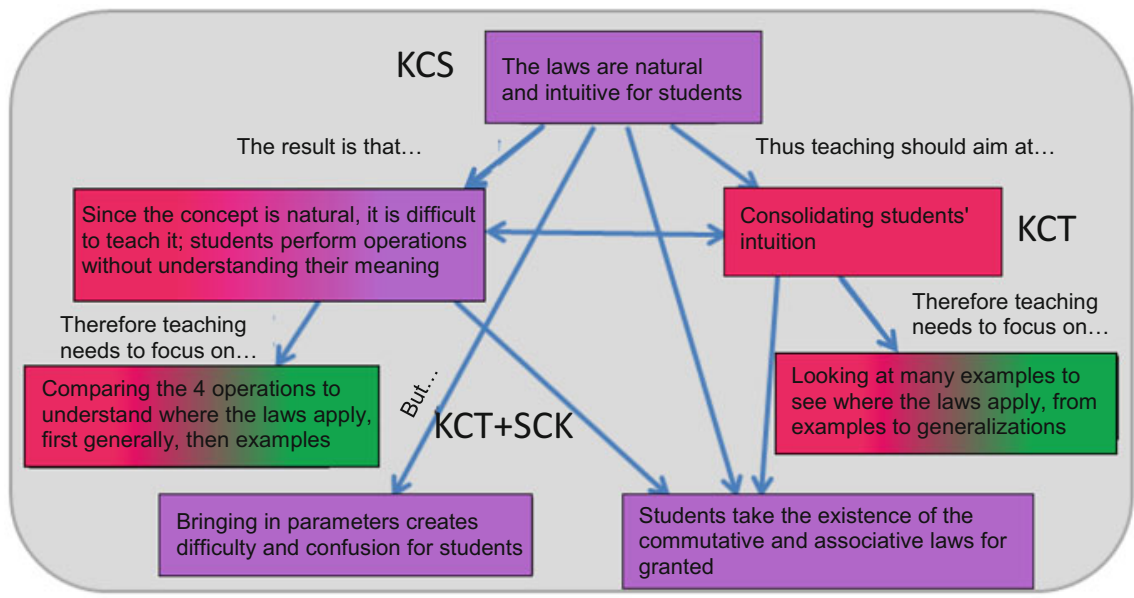

Fig. 16.3 One of the "discussion maps" describing the discussion before watching the video "The commutative and associative laws" (For interpretation of the references to color in this figure, the reader is referred to the web version of this article) 
While watching the episode, each couple of teachers was requested to focus on one of the lenses comprising SLF. Then, in the plenary, observations were shared and discussed by all participants. On the whole, teachers were surprised by the episode, since the main mathematical idea raised by the filmed teacher was not considered by the group earlier. One of them described the teachers goal as " $u n$ dermining the perception that an operation can either satisfy both the associative and commutative laws or none of them". The teachers used concepts from set theory to express this idea (see Fig. 16.5), noting that addition and multiplication are in the intersection of the commutative operations and the associative operations sets, while subtraction and division are in the complement of the union of these sets. While students might hold the misconception that the other possible two sets are empty, the lesson demonstrates that operations exist in all possible sets. Teachers also discussed the use of finite operation tables. Some teachers asserted that operations on small finite groups are not equivalent, mathematically and pedagogically, to operations defined on the real numbers. Thus, they challenged the group to find an operation, defined on the real numbers and relevant to students' school learning, for which only one of the laws holds. Eventually, two such

\begin{tabular}{|c|c|c|c|c|c|}
\hline \multirow{5}{*}{ Operation table presented: } & $\begin{array}{l}\text { Operation that returns the } \\
\text { first number in the pair }\end{array}$ & \multicolumn{4}{|c|}{$\begin{array}{c}\text { Arbitrary operation on all } \\
\text { possible pairs made of } a, b, c\end{array}$} \\
\hline & \multirow{4}{*}{\begin{tabular}{|l|l|}
$\Delta$ & 0 \\
0 & 0 \\
1 & 1 \\
2 & 2 \\
3 & 3 \\
\end{tabular}} & * & $a$ & $\mathrm{~b}$ & c \\
\hline & & a & $a$ & $\mathbf{a}$ & $\mathrm{b}$ \\
\hline & & $\mathrm{b}$ & $a$ & c & $\mathrm{b}$ \\
\hline & & $\mathrm{c}$ & $\mathrm{b}$ & $\mathrm{b}$ & $a$ \\
\hline Commutative law & $x$ & \multicolumn{4}{|c|}{$\checkmark$} \\
\hline Associative law & $\checkmark$ & \multicolumn{4}{|c|}{$x$} \\
\hline
\end{tabular}

Fig. 16.4 Examples of operations discussed in the video "The commutative and associative laws"

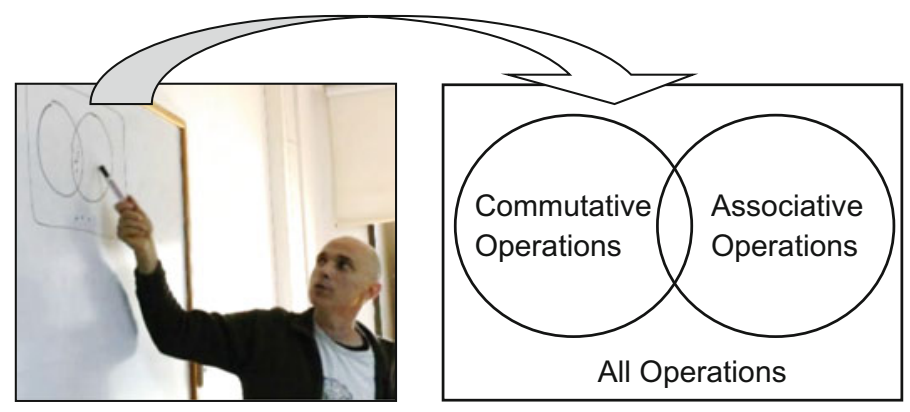

Fig. 16.5 A teacher presenting the mathematical idea of the episode using set theory 


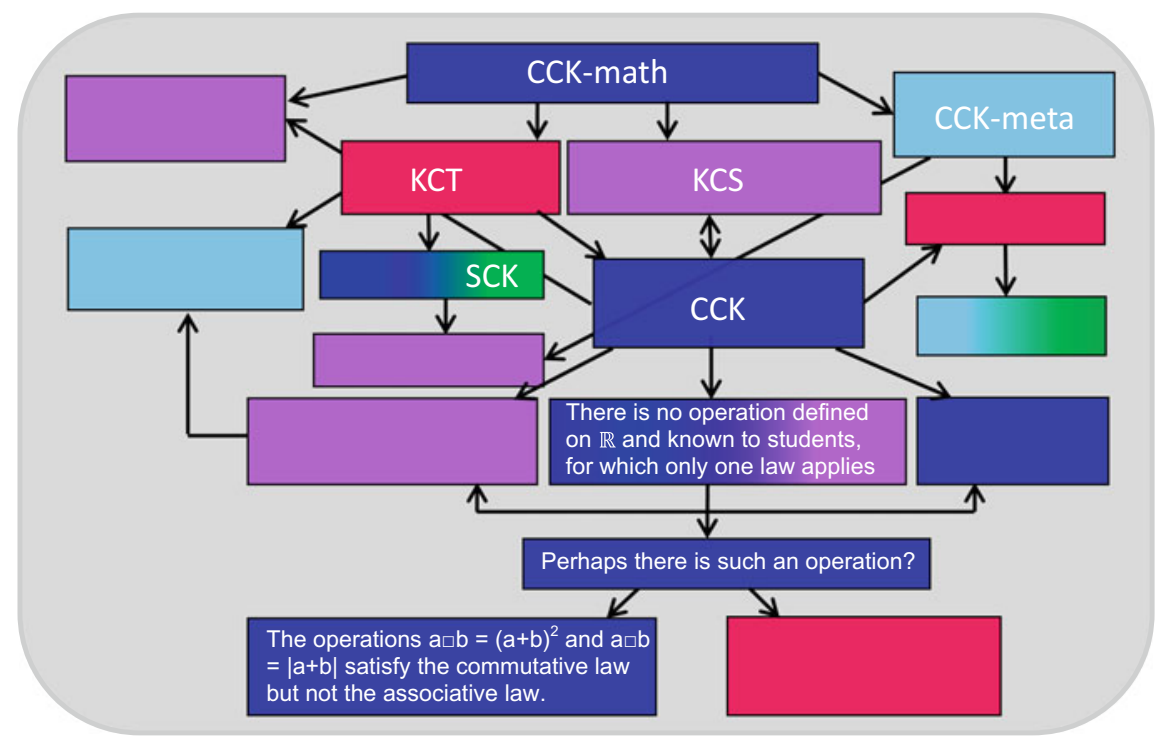

Fig. 16.6 A schema of the "discussion map" describing the discussion after watching the video "The commutative and associative laws" (For interpretation of the references to color in this figure, the reader is referred to the web version of this article)

examples were found: $a \square b=(a+b)^{2}$ and $a \square b=|a+b|$. In both cases the operation satisfies the commutative law but not the associative law.

This part of the discussion was also coded in terms of the MKT categories and formed into a discussion map. Figure 16.6 presents the schema of this map, illustrating the colored MKT categories (since space is limited, only several units are presented in words within this map). Comparing the discussion maps before and after the video was observed and analyzed by teachers, reveals that watching the video triggered a shift in the participants' utterances from pedagogical considerations towards the eliciting of more mathematical ideas, as was evident from the considerable increase in the units coded as Common Content Knowledge (CCK). In terms of quantification, the percentage of units coded as CCK before and after observing the video was 20 and $45 \%$, respectively.

The findings from the case of "the commutative and associative laws" video are representative of other findings as well. For example, at Site (b), teachers explored various definitions of an inflection point, after watching an 11th grade Calculus class. In the video, the teacher discussed with her students the concept of concavity of functions, leading to the definition of inflection points as points where the graph changes from concavity upwards to concavity downwards or vice versa. This was then translated into a working tool, associating inflection points of $f(x)$ with the extreme points of $f^{\prime}(x)$ or the zeros of $f^{\prime \prime}(x)$.

The video triggered a discussion about possible deficiencies of this tool, focusing on the following question: What about an inflection point where the first or 


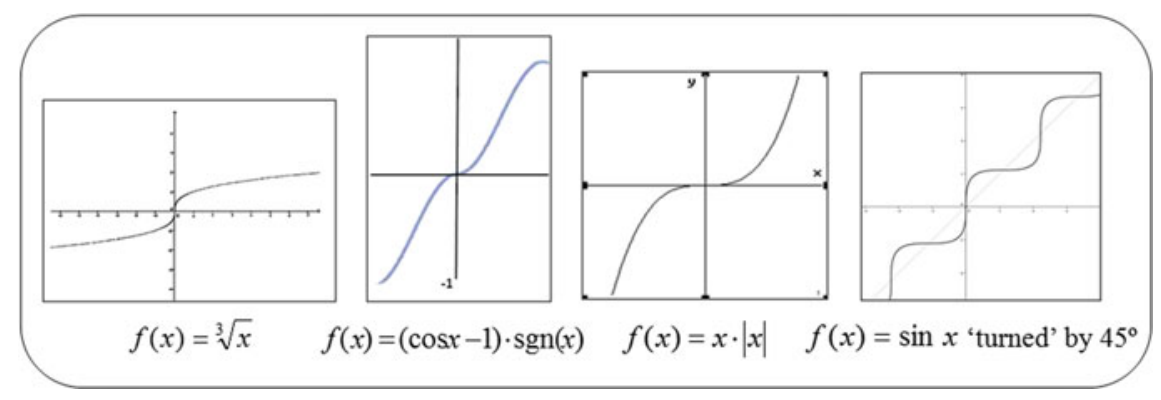

Fig. 16.7 Examples generated by teachers for functions $f(x)$ that have an inflection point at 0 but $f^{\prime}(0)$ and/or $f^{\prime \prime}(0)$ do not exist

the second derivatives do not exist? The group became motivated to find counterexamples where $f(x)$ has an inflection point in $x_{0}$ but $f^{\prime}\left(x_{0}\right)$ or $f^{\prime \prime}\left(x_{0}\right)$ do not exist, and found a graphic example but not an algebraic representation of such a function. Following the session, in an intense and rich email exchange, teachers found and shared different counterexamples, as described in Fig. 16.7.

As a result, the group reached a consensus about the accuracy of definitions of inflection points that are customarily presented in advanced calculus classrooms. The new collectively generated MKT also included valuable pedagogical suggestions offered by participants, such as the idea to have students find their own counterexamples to the "rule" that identifies inflection points with $f^{\prime \prime}(x)=0$. Another opportunity to extend knowledge evolved during the session, when the goals of the videotaped teacher were discussed. Participants attempted to justify the teacher's choice of presenting an inaccurate working definition by ascribing to her two major considerations: Firstly, students may not be ready to grasp the correct definition, which requires advanced thinking, and, secondly, functions such as $x \cdot|x|$ are not included in the curriculum and in the final exams. This part of the discussion opened a debate on more general questions: How far should teachers go beyond what is delimited by the curriculum? To what extent are we allowed to "sacrifice" mathematical rigor in favor of our students' immediate practical interests?

To sum up this section, the cases analyzed above suggest that SLF-based peer discussions around videotaped lessons can be a powerful tool for prompting the growth and refinement of relevant mathematical knowledge for teaching.

\subsubsection{Enhancement of Reflection on the Mathematics Teaching Practice}

In this section I will demonstrate, through representative examples, how viewing videotaped mathematics lessons of unknown teachers, using lenses included in 
SLF, contribute to the development of rich reflection on the practice of teaching mathematics in general and on one's own practice in particular. I will focus here on two lenses: tasks and beliefs.

\subsubsection{Reflecting Through the Lens of Tasks}

The video enables teachers to watch a "task in action", how it is implemented, the nuances in introducing it, how students attempt to solve it, and how the teacher addresses the students' reactions. We refer to this as an "a posteriori task analysis", which may be very different from the somewhat limited "a priori analysis", i.e., examining the same task as it appears in a written text. This turned out to be a very engaging activity in VIDEO-LM courses. For example, when we investigated what teachers talked about in sessions around a Japanese video, in which a challenging geometrical problem was given to eighth grade students, we found that $29.3 \%$ of the teachers' talk was devoted to the task, its characteristics, affordances, and limitations, how it was presented and how students handled it (Karsenty and Schwarts 2016; Schwarts 2016). This collective analysis led many teachers to relate to the kinds of tasks and problems they use in their own classrooms, as illustrated in the following teacher citations, taken from PD sessions or from written reflections submitted after the course:

- “There's an embarrassment here, do I surprise my students at all, occasionally? It's difficult to deal with this embarrassment [...] Seeing this unusual problem raises the question of how many times do I do that, and what it tells about the way I teach" (PD session, Site a)

- "Many times I try to select problems that are unique, special [...], it's not always simple, sometimes I have them from last year, sometimes I find them accidently [...], and then once you do the irregular stuff, the other problems they can handle" (PD session, Site c)

- "There are beautiful proofs using areas, but in fact we actually never do them" (PD session, Site e)

- "Watching this Japanese lesson left me with frustration, that I as a teacher mainly teach technique, solving algorithms and not much beyond that, I feel chained to the time constraints. Or is this just an excuse for not being creative?" (written reflection).

- 'I'm in my 22nd year of teaching, and I look at this thing and I know that I'm taking this today [...] I'm not going to be this teacher in this classroom but I definitely leave here asking myself what I'm going to do with it tomorrow, in my classes" (PD session, Site a).

Talking about tasks and their implementation in class may also evoke reflections about risks that teachers take (or refrain from taking) when choosing tasks for students. Following a discussion on a videotaped lesson on sequences, given in a low-track class, one of the teachers wrote in his reflection: 
In this session teachers occasionally raised doubts (that I also feel sometimes) about the ability of students to deal with the tasks we give them. The one who phrased it in the best way was Sam, who said "I don't have the courage to throw my students into it, just like that, on their own...". I think that this is the heart of the matter, it is us who don't have courage to let them strive. If we dare a little more, so will they. (written reflection, emphasis in original)

In this case, the teacher raises considerations of what he calls "courage," related to selecting tasks that students may struggle with. In another case, teachers talked about selecting tasks that are challenging for teachers. The conversation below took place in Site (d):

677 T1: What does a teacher do if he just now opened the textbook, saw some tasks, tried to solve them and did not succeed. Does he take it to class? [...]

685 Facilitator: Do I take to my classroom something that I cannot solve?

686 T2: Of course not! Are you kidding me?

687 T3: Surely not

688 T1: I don't know, maybe yes

689 T2: What [do you mean] yes?

691 Facilitator: Why?

692 T1: Why? Because if I come to class with the approach of "let's learn together" ...

693 T2: Let's think together?

694 T1: Let's think together, here, there are certain things that I too...

In both cases, clearly the discussion through the lens of tasks is interrelated with the teachers' beliefs regarding their role as teachers, although this interrelation remains implicit. This connection is not surprising; the issue of how teachers' beliefs shape their practice has been widely studied (e.g., Schoenfeld 1998; Li and Moschkovich 2013). Thus, we acknowledge that in fact the use of most of the lenses comprising SLF (i.e., goals, tasks, interactions, and dilemmas) is likely to be guided by the beliefs teachers hold. This is one of the main sources for our decision to explicitly include conversations about beliefs in VIDEO-LM courses, or in other words, to incorporate the lens of beliefs as one of the six lenses. In the next section I elaborate on possible gains of using the lens of beliefs.

\subsubsection{Reflecting Through the Lens of Beliefs}

Facilitating discussion about beliefs is a delicate matter; for many teachers, this theoretical construct is foreign, thus it needs to be carefully presented. As shown in Table 16.1 above, some the questions we focus on within this lens are: On the basis of the observed teacher's actions, what may be her views about the nature of mathematics as a discipline? How does she perceive her role? What may be her ideas about what "good mathematics teaching" is? The exercise of inferring and attributing beliefs to another teacher is not a trivial one. However, it often triggers catalytic comments, especially in later stages of the course, when teachers begin to 
internalize the SLF language and connect the analysis to their own practices. This was demonstrated vividly in one of the PD sessions at Site (b). The topic of the lesson watched was sketching, for a given function $f(x)$, the graphs of $e^{f(x)}$ and $\ln f(x)$. The teaching in this lesson was frontal, with the teacher's tight control over the development of the mathematical knowledge. Students appeared to be highly engaged in the questions posed by the teacher, who never left her position near the board. In the discussion, one teacher said:

The lesson really challenges our beliefs. [...] If you'd ask me at the beginning, before watching the video, what... how should a lesson look like, I would have said many nice things $[\ldots]$ such as you need to have a discussion, you need to have shared thinking, students should experiment right and wrong things, you need to have interaction in the class, and dynamics, and then suddenly I see something that... doesn't have these things there's no discussion, or just a very short one, and I'm looking at it and I say 'what a beautiful lesson!' [...] so now I have an internal conflict, really, I have an internal conflict, because on the one hand everything I know about teaching is missing here, but on the other hand I like what I see. So I'm trying to settle this dissonance, so I say okay, maybe it's class dependent, maybe it's students dependent.

This citation indicates that, when given the opportunity to directly speak about beliefs, teachers may re-inspect their most deep convictions and practices and confront the complexities of teaching. This may or may not lead to changes in one's own beliefs, or in one's practice, but it increases teachers' awareness to various decisions they make, which are often left implicit.

\subsection{Discussion}

VIDEO-LM professional development courses provide opportunities for secondary mathematics teachers to watch authentic lessons and discuss them in a supportive and non-evaluative environment. In the previous section, I presented indications of the development and refinement of mathematical knowledge for teaching among courses participants, as well as enhancement of focused reflection on various aspects of the mathematics teaching practice. One of the interesting questions to be raised in light of these findings concerns the mechanisms by which such developments may take place. In this specific context, I define "mechanisms" as "actions, thinking processes, or behaviors occurring during the activities of watching a videotaped lesson and engaging in an SLF-based discussion". Accordingly, the aim is to identify and characterize mechanisms that possibly enable, or account for, observed outcomes of reflection and knowledge growth that are associated with participation in VIDEO-LM courses. Pointing to such explanatory mechanisms is an elusive pursuit, as it is difficult to determine a causal connection between certain features of a PD activity and observed products of the PD. Nevertheless, several mechanisms can by mentioned as a starting point for further exploration: 
I. Using an explicit "language" and a multi-focused tool. The SLF framework and norms can be seen as a new language that teachers get acquainted with. The explicitness of SLF and its presence in all sessions function as an organizer of experience, in the sense described in classic psycholinguistics: "Language enables us to extract from the fleeting mass of phenomena the common elements or qualities essential for our experience, and to give them permanence" (Hörmann 1979, p. 11). This possible mechanism is reflected, for instance, in the following citation from the written feedback of a participant in Site (a):

These are really tools that now I use to look at lessons, and also when I plan lessons $[\ldots]$ everything suddenly has names, selecting tasks as well. There are many kinds of spectacles that now became natural to me.

II. Comparing and contrasting. Comparison to others is a powerful mechanism, encountered by people on a daily basis (Mussweiler et al. 2004). Although such comparisons can often be unproductive, situations in which a subtle comparison to other professionals is triggered carry an opportunity to reflect on one's goals and decisions. VIDEO-LM's agenda does not include direct comparisons, yet these are apparently unavoidable, and in most PD conversations teachers switch back and forth from analyzing actions of the videotaped teacher to self-inspections of their own teaching, as shown, for instance, in Sect. 16.4.2.1. In some of the written feedbacks we found even "meta-reflections" on this process, for example:

During the video watching and discussions [...] I found myself engaged in questions: Where do I stand? What would I have done? How come I never thought of this? [...] In what ways am I different? What should I keep? What should I change?

III. Intentional stepping into another person's shoes. This mechanism is explicitly present in SLF-based discussions, as described in Sect. 16.2.2. We invite teachers to infer and attribute goals, dilemmas, and beliefs to the filmed teacher; Rather than evaluating the teacher, they are requested to seek possible reasons for certain decisions made. One of our facilitators developed a unique strategy for this request: A chair is put in the front of the room, and whoever wants to offer an analysis of a specific occurrence is asked to sit in that chair and speak in a first person voice, attempting to adopt the perspective of the teacher in the video. This unusual stance has a considerable influence on participants, as illustrated in the following citation by a teacher who was also a regional teacher mentor employed by the Ministry of Education:

[It] completely changed the nature of my observations on teachers' lessons [...] all of the conversation, the conversation that I hold now with a teacher, after visiting his classroom for observation, is more like "what's your motivation, and what brought you [to do this], and what were your considerations", and it leads to a different kind of meaningful conversations. [...] Something changed, even in the way I observe. 
IV. Postponing judgment. In the first PD sessions, the facilitators establish this norm almost "forcefully"; Instead of judgmental comments about the filmed teacher's decisions, participants are asked to consider alternative paths and their consequent tradeoffs. Later on in the course, this norm seems to be internalized as an almost automatic mechanism, and judgmental viewpoints are replaced with the need for mindful decisions, as reflected in the following feedback:

We all teach fine, the point is to understand what you're doing, why do you do it, and do you really agree with what you decided to do. If you agree, fine, but if you don't - go and fix it! But be aware of what you did. I never thought about that.

V. Discovering collective wisdom. Hearing opinions expressed by peer teachers, rather than by "authorities" such as facilitators or researchers, seems to have the potential of convincing teachers to consider a change in their own opinion. We encountered an interesting example of this mechanism in the case of Daniela (pseudonym), a teacher who argued passionately that the Japanese lesson could never be successfully duplicated in an Israeli classroom. She nevertheless decided to try it in her classroom and reported back in the next session on its overwhelming success. When asked later why she decided to act against her intuition, she said:

The fact that people were in favor. I'm trying to figure out if, let's say, everyone was against it, would I still want to try this lesson? Probably the fact that there were other people that said... that supported this lesson and said "it might be a good thing, it might be beneficial." [...] Yeah, it definitely reinforced it $[\ldots]$ Other opinions that upset me is actually a fascinating thing, to try them, because, again, who says I'm in this place that is guaranteed? The minute this opinion was strengthened by opinions of the participants, and people justified their stance, so I was even more interested to check this out.

VI. Exposure to a variety of styles and methods. The videotaped lessons observed during a typical VIDEO-LM course are varied in terms of teaching styles, approaches to teaching core subjects in the curriculum, use of technology, and more. Possibly, this diversity serves as an eye opener by itself and has an impact on teachers' readiness to elicit ideas of their own and reflect on their practice. The following citation from a written reflection illustrates this:

It's a pleasure to look at different teachers and diverse teaching styles that often were a mirror to my own conduct and sometimes were a source for inspiration and pondering.

I end this paper with a last citation, taken from a teacher's written reflection, that conveys the spirit of VIDEO-LM and the kind of teacher learning we aspire to nurture within it:

Theoretically, I know that there is an infinite variety of teachers that I can regard as "good teachers" and still they will be different from one another, and in various decision crossroads they may take totally opposite decisions. However, 
each time I witness this it is a refreshing discovery, and I feel that slowly slowly it wears out my inherent belief that there are absolute "rights" and "wrongs" in teaching too.

Acknowledgements This study was supported by the Israel Science Foundation, Grant \#1539/15, and by the Israel Trump Foundation for Science and Mathematics Education, Grant \#7/143. I wish to thank my colleague and friend Abraham Arcavi, with whom I co-direct the VIDEO-LM project, for a most valuable and productive partnership.

\section{References}

Arcavi, A., \& Schoenfeld, A. H. (2008). Using the unfamiliar to problematize the familiar: The case of mathematics teacher in-service education. Canadian Journal of Science, Mathematics, and Technology Education, 8(3), 280-295.

Ball, D. L., Thames, M. H., \& Phelps, G. (2008). Content knowledge for teaching: What makes it special. Journal of Teacher Education, 59(5), 389-407.

Borko, H., Koellner, K., Jacobs, J., \& Seago, N. (2011). Using video representations of teaching in practice-based professional development programs. ZDM-The International Journal of Mathematics Education, 43(1), 175-187.

Brophy, J. (Ed.). (2004). Using video in teacher education. The Netherlands: Elsevier.

Clarke, D., Hollingsworth, H., \& Gorur, R. (2013). Facilitating reflection and action: The possible contribution of video to mathematics teacher education. Sisyphus - Journal of Education, 1(3), 94-121.

Coles, A. (2013). Using video for professional development: The role of the discussion facilitator. Journal of Mathematics Teacher Education, 16(3), 165-184.

Coles, A. (2014). Mathematics teachers learning with video: The role, for the didactician, of a heightened listening. ZDM-The International Journal of Mathematics Education, 46(2), 267 278.

Danielson, S. (2013). The framework for teaching evaluation instrument (2013 ed.). Princton, NJ: The Danielson Group.

Glaser, B. G., \& Strauss, A. L. (1967). The discovery of grounded theory: Strategies for qualitative research. New York: Aldine.

Gaudin, C., \& Chaliès, S. (2015). Video viewing in teacher education and professional development: A literature review. Educational Research Review, 16, 41-67.

Goffree, F., \& Oonk, W. (2001). Digitizing real teaching practice for teacher education programmes: The MILE approach. In F. L. Lin \& T. J. Cooney (Eds.), Making sense of mathematics teacher education (pp. 111-145). The Netherlands: Springer.

Hill, H. C., Blunk, M., Charalambous, C., Lewis, J., Phelps, G. C., Sleep, L., et al. (2008). Mathematical knowledge for teaching and the mathematical quality of instruction: An exploratory study. Cognition and Instruction, 26, 430-511.

Hörmann, H. (1979). Psycholinguistics: An introduction to research and theory. New York: Springer.

Jaworski, B. (1990). Video as a tool for teachers' professional development. British Journal of In-Service Education, 16(1), 60-65.

Karsenty, R., Arcavi, A., \& Nurick, Y. (2015). Video-based peer discussions as sources for knowledge growth of secondary teachers. In K. Krainer \& N. Vondrová (Eds.), Proceedings of the 9th Congress of the European Society for Research in Mathematics Education (pp. 28252832). Prague: ERME.

Karsenty R., \& Schwarts, G. (2016). Enhancing reflective skills of secondary mathematics teachers through video-based peer discussions: A cross-cultural story. Paper presented in 
TSG-50 of the 13th International Congress on Mathematical Education. Hamburg, Germany, July 2016.

Lefstein, A., \& Snell, J. (2014). Better than best practice: Developing teaching and learning through dialogue. New York: Routledge.

Li, Y., \& Moschkovich, J. N. (2013). Proficiency and beliefs in learning and teaching mathematics-Learning from Alan Schoenfeld and Günter Törner. Rotterdam: Sense Publishers.

Mussweiler, T., Rüter, K., \& Epstude, K. (2004). The ups and downs of social comparison: Mechanisms of assimilation and contrast. Journal of Personality and Social Psychology, 87(6), 832.

Nurick, Y. (2015). The crystallization of mathematical knowledge for teaching of high school teachers in video-based peer discussions (Unpublished master's thesis). Weizmann Institute of Science (in Hebrew).

Nemirovsky, R., \& Galvis, A. (2004). Facilitating grounded online interactions in video-case-based teacher professional development. Journal of Science Education and Technology, 13(1), 67-79.

Santagata, R., \& Yeh, C. (2013). Learning to teach mathematics and to analyze teaching effectiveness: Evidence from a video-and practice-based approach. Journal of Mathematics Teacher Education, 17(6), 491-514.

Schoenfeld, A. H. (1998). Toward a theory of teaching-in-context. Issues in Education, 4(1), 1-94.

Schoenfeld, A. H. (2010). How we think: A theory of goal-oriented decision making and its educational applications. New York: Routledge.

Schwarts, G. (2016). Characterizing video-based peer discussions of Israeli mathematics teachers watching a Japanese lesson (Unpublished master's thesis). Weizmann Institute of Science (in Hebrew).

Seago, N., Jacobs, J., \& Driscoll, M. (2010). Transforming middle school geometry: Designing professional development materials that support the teaching and learning of similarity. Middle Grades Research Journal, 5(4), 199-211.

Sherin, M. G. (2004). New perspectives on the role of video in teacher education. Advances in Research on Teaching, 10, 1-27.

Sherin, M. G., Jacobs, V. R., \& Philipp, R. A. (Eds.). (2011). Mathematics teacher noticing: Seeing through teachers' eyes. New York: Routledge.

Sherin, M. G., \& van Es, E. A. (2009). Effects of video participation on teachers' professional vision. Journal of Teacher Education, 60(1), 20-37.

van Es, E. A., \& Sherin, M. G. (2008). Mathematics teachers learning to notice in the context of a video club. Teaching and Teacher Education, 24, 244-276.

Open Access This chapter is licensed under the terms of the Creative Commons Attribution 4.0 International License (http://creativecommons.org/licenses/by/4.0/), which permits use, sharing, adaptation, distribution and reproduction in any medium or format, as long as you give appropriate credit to the original author(s) and the source, provide a link to the Creative Commons license and indicate if changes were made.

The images or other third party material in this chapter are included in the chapter's Creative Commons license, unless indicated otherwise in a credit line to the material. If material is not included in the chapter's Creative Commons license and your intended use is not permitted by statutory regulation or exceeds the permitted use, you will need to obtain permission directly from the copyright holder. 